\title{
Sleep habits and complaints of adults in the city of São Paulo, Brazil, in 1987 and 1995
}

M.L.N. Pires, A.A. Benedito-Silva, M.T. Mello, S. Del Giglio, C. Pompeia and S. Tufik
Departamento de Psicobiologia, Escola Paulista de Medicina, Universidade Federal de São Paulo, São Paulo, SP, Brasil

\section{Correspondence}

M.L.N. Pires

Departamento de Psicobiologia EPM, UNIFESP

Rua Napoleão de Barros, 925

04024-002 São Paulo, SP

Brasil

Fax: +55-11-5572-5092

E-mail:mlnpires@psicobio.epm.br

Research supported by

FAPESP/CEPID (No. 98/14303-3) and

Associação Fundo de Incentivo à

Psicofarmacologia (AFIP).

Received December 1, 2007

Accepted July 4, 2007

\begin{abstract}
This study compares the prevalence of complaints of insomnia, excessive diurnal sleepiness, parasomnias, and sleep habits of the adult population in the city of São Paulo, Brazil, estimated in surveys carried out in 1987 and 1995. Representative samples of 1000 adult residents per survey were interviewed using a validated structured sleep questionnaire, the "UNIFESP Sleep Questionnaire". Difficulty maintaining sleep, difficulty initiating sleep and early morning awakening, occurring at least three times a week, were reported in 1987 and 1995 , by $15.8 / 27.6,13.9 / 19.1$, and $10.6 / 14.2 \%$ of the interviewees, respectively, significantly increasing throughout time. These sleep problems were more often found among women. Frequencies of excessive diurnal sleepiness and sleep attacks were unchanged comparing 1987 with 1995 (4.5 vs 3.8 and 3.1 vs 3.0\%, respectively). Parasomnia complaints remained unchanged, with the exception of leg cramps, which doubled in prevalence from 1987 to 1995 (2.6 to $5.8 \%)$. Snoring was the most common parasomnia (21.5\% in 1995), reported more often by men than by women, and somnambulism was the least common (approximately 1\%). Besides sleeping slightly less, interviewees went to bed and woke up later in 1995. Approximately $12 \%$ of the subjects in both surveys had consulted a physician due to sleep problems and 3.0\% reported habitual use of sleep-promoting substances in 1995. Overall, there was a significant increase in insomnia complaints from 1987 to 1995 in the general population of the city of São Paulo. This major change over a little under a decade should be considered as an important public health issue.
\end{abstract}

Key words

- Sleep

- Sleep disorders

- Insomnia

- Diurnal sleepiness

- Parasomnias

- Epidemiology

- Sleep habits

\section{Introduction}

Sleep disorders, particularly insomnia, adversely affect quality of life, performance, memory and concentration, increase the risk of accidents and are associated with psychiatric and medical conditions such as heart disease and chronic pain and increased mor- tality rates $(1,2)$. Although sleep disorders are recognized as a public health problem (2), information on their epidemiology is still limited when it comes to changes over time. Data from South America are scarce when compared to the knowledge accumu- 
lated from studies conducted in North America, Europe and Asia (3). In Brazil, where sleep medicine is growing in importance, the absence of such information is a barrier to the efforts of promoting public health.

In 1987 (4) and 8 years later, in 1995, two cross-sectional household surveys, based on the "UNIFESP Sleep Questionnaire", were carried out in order to estimate the prevalence of sleep complaints among adults living in the city of São Paulo, SP, Brazil, and to evaluate changes with time. This Brazilian city, which is cut by the Tropic of Capricorn, is the largest in South America, with an estimated population of 10 million in both 1987 and 1996, composed of multiple ethnic groups. The city of São Paulo is one of the major agglomerations in the world, ranking in the 4th and 3rd positions in 1987 and 1995, respectively, and expected to be in the 2nd position in 2010 (5).

The objective of the present study was to compare the estimates of insomnia, excessive diurnal sleepiness and parasomnia complaints obtained in surveys carried out in 1987 and 1995. Additionally, we sought to examine some aspects related to sleep behavior, such as sleep timing, sleep duration, physician consulting due to sleep problems, and the use of sleep-promoting substances.

\section{Material and Methods}

\section{Samples}

The total population of the city of São Paulo maintained a steady value of 10,000,000 between 1980 and 2000 (6). Approximately $62 \%$ are 20 years of age or over, considered, herein, as "adult population", which includes both genders. The criterion for sampling was probabilistic. Representative samples of the adult population were determined by a stratified procedure. Twelve districts ( 8 original and 4 complementary ones) were selected by drawing lots from four regions in the city of São Paulo previously classified as homogenous regarding the distribution of the economically active population (adapted from Ref. 7). The number of districts was arbitrarily selected, irrespective of the population of each region. The census sectors of each district were listed in decreasing order, according to average family income, and a total of 60 (50 original and 10 complementary) census sectors, each with approximately 200 homes, were sampled from each district, taking samples at fixed intervals in order to represent all income levels. Districts and census sectors were defined according to the IBGE (6). The selection of 25 homes number defined a priori; permanently occupied private residences, excluding buildings such as hospitals, schools and hotels) in each sector was carried out systematically by randomly picking the first, then skipping a certain interval of homes defined by the total number of homes of the sector divided by 25 , following thereafter a specified order. When apartment buildings were encountered, each apartment was considered to be a home and counting proceeded from the top floor down. Whenever interview obstruction occurred due to refusal by security personnel to reach the selected person, communication was first established by telephone or by mail.

The selection of the individual to be interviewed in each residence was determined using random criteria. After three failed attempts to locate the target interviewee, or whenever one of the following occurred: total refusal, physical or mental impairment, obstruction by a family member, or inability to comply due to a trip, hospitalization or an inappropriate schedule considering the safety of the interviewer, a substitute was provided with equivalent socio-economic profile, the same gender, age group, and living in the same census sector. The substitution rate was 17 and $13 \%$ in 1987 and 1995, respectively. "Complementary" districts and district sectors refer to sampling carried out due to substitutions. The final samples consisted 
of 441 men and 559 women in 1987 and 426 men and 574 women in 1995. This total of 1000 per survey was considered to be representative to assess the prevalence of the main sleep disorders with a sampling error below 5\% and confidence interval within $95 \%$, based on epidemiological studies carried out elsewhere $(8,9)$.

\section{Questionnaire}

The "UNIFESP Sleep Questionnaire" developed by Braz et al. (4) was used in both surveys, having been validated by medical examination and polysomnography, yielding an overall sensitivity of $70 \%$ and specificity of $75 \%$. Each subject was interviewed individually in his/her residence by professional survey takers who had received extensive training on the questionnaire. The first group of questions asked about sociodemographic characteristics, such as gender, age, marital status, and socio-economic status. The age brackets used were: 20-30, 31-40, 41-50, $\geq 51$. Each interviewee was classified as lower, middle, or upper socioeconomic class according to the system proposed by the Brazilian Association of Market Research Institutes (ABIPEME, Associação Brasileira dos Institutos de Pesquisa de Mercado) (10).

The second group of questions inquired about sleep, such as time to go to bed and getting up, its problems and their frequency. Insomnia was assessed through complaints of difficulty initiating sleep, difficulty maintaining sleep, or awakening earlier than desired and not resuming sleep. Excessive daytime somnolence was assessed through complaints of diurnal sleepiness with impairment of daytime activities and sleep attacks. The interviewees were asked about the frequency at which they experienced these sleep problems and the answers were rated on a 7point scale: 1) never, 2) less than once a month, 3) once a month, 4) two to three times a month, 5) one to two times a week, 6) three to six times a week, 7) daily. Those who answered 6 or 7 were considered to have a significant complaint of insomnia or excessive diurnal somnolence.

The questionnaire also included a number of items concerning parasomnias, defined according to the following items: 1) nocturnal bruxism; nocturnal leg cramps and snoring were considered to be habitual experiences when they occurred at least three times a week; 2) somnambulism, nightmares and attacks of sleep paralysis were considered to be habitual experiences when they occurred at least once a month.

The interviewees were also asked if they had sought the help of a physician due to their sleep problems and if they had used medication to help them sleep (with no distinction between prescribed, over-the-counter or herbal medicines).

The protocol was approved by the Ethics Board and all interviewees signed informed consent forms.

\section{Statistical analysis}

Results are reported as proportions and the corresponding associated lower and upper limits of the $95 \%$ confidence interval (95\% CI) and comparisons between them were made using the $\mathrm{Z}$ statistics. In order to perform calculations involving sleeping hours, reported bedtime or waking hours after 24:00 and before 12:00 o'clock were converted by the addition of $24 \mathrm{~h}$. After analysis, values were converted back. Comparisons related to socio-demographic characteristics were analyzed by the chi-square test and contrasts between sleep onset time and duration were carried out by the Student $t$-test. A P value of less than 0.05 was considered to be significant.

\section{Results}

Table 1 shows the distribution of the interviewees in each survey according to 
Table 1. Socio-demographic characteristics of the study population.

\begin{tabular}{lccc}
\hline & 1987 & 1995 & $\chi^{2}$ (d.f. =1), P \\
\hline $\begin{array}{l}\text { Gender } \\
\quad \text { Male }\end{array}$ & & & \\
$\quad$ Female & $44.1 \%(41.1-47.2)$ & $42.6 \%(39.6-45.7)$ & $0.5, \mathrm{~ns}$ \\
& $55.9 \%(52.8-58.9)$ & $57.4 \%(54.3-60.4)$ & \\
Marital status & & & \\
$\quad$ Single & $18.9 \%(16.6-21.4)$ & $22.9 \%(20.4-25.6)$ & $4.8, \mathrm{P}<0.05$ \\
$\quad$ Married & $66.5 \%(63.5-69.4)$ & $59.0 \%(55.9-62.0)$ & $12.0, \mathrm{P}<0.05$ \\
$\quad$ Separated & $4.6 \%(3.5-6.1)$ & $6.4 \%(5.0-8.1)$ & $3.1, \mathrm{~ns}$ \\
$\quad$ Widowed & $10.0 \%(8.3-12.0)$ & $11.7 \%(9.9-13.8)$ & $1.5, \mathrm{~ns}$ \\
& & & \\
Socio-economic level & & & \\
$\quad$ Upper & $36.0 \%(26.1-49.4)$ & $31.9 \%(29.1-34.9)$ & $3.8, \mathrm{P}<0.05$ \\
$\quad$ Middle & $32.2 \%(29.4-35.2)$ & $31.6 \%(28.8-34.6)$ & $0.1, \mathrm{~ns}$ \\
$\quad$ Lower & $31.8 \%(29.0-34.8)$ & $36.5 \%(33.6-39.5)$ & $4.9, \mathrm{P}<0.05$ \\
& & & \\
Age brackets & & & \\
$20-30$ & $25.3 \%(22.7-28.1)$ & $25.0 \%(22.4-27.8)$ & \\
$\quad 31-40$ & $28.2 \%(25.5-31.1)$ & $24.8 \%(22.2-27.6)$ & \\
$41-50$ & $19.3 \%(17.0-21.9)$ & $18.9 \%(16.6-21.4)$ & \\
$\geq 51$ & $29.1 \%(26.4-32.0)$ & $31.3 \%(28.5-34.2)$ & \\
\hline
\end{tabular}

Data are reported as percent with confidence interval at $95 \%$ in parentheses (chisquare test).

Table 2. Sleeping times and sleep duration found in surveys carried out in 1987 and 1995 in the city of São Paulo.

\begin{tabular}{lcc}
\hline & 1987 & 1995 \\
\hline $\begin{array}{l}\text { Time of going to bed } \\
\text { Monday-Thursday }\end{array}$ & $22.45 \pm 1.84$ & \\
Friday & $22.79 \pm 1.94$ & $23.29 \pm 1.75^{*}$ \\
Saturday & $22.89 \pm 2.12$ & $23.51 \pm 1.92^{*}$ \\
Sunday & $21.98 \pm 1.72$ & $23.99 \pm 2.08^{*}$ \\
& & $23.29 \pm 1.74^{*}$ \\
Time of waking up & & \\
Monday-Thursday & $6.27 \pm 1.76$ & $6.89 \pm 2.34^{*}$ \\
Friday & $6.22 \pm 1.34$ & $6.91 \pm 2.36^{*}$ \\
Saturday & $6.86 \pm 1.65$ & $7.43 \pm 3.08^{*}$ \\
Sunday & $6.98 \pm 1.72$ & $7.68 \pm 3.23^{*}$ \\
& & \\
Sleep duration & & $7.60 \pm 4.26$ \\
$\quad$ Monday-Thursday & $7.82 \pm 3.25$ & $7.40 \pm 4.62$ \\
$\quad$ Friday & $7.43 \pm 2.79$ & $7.44 \pm 6.91^{*}$ \\
Saturday & $7.97 \pm 3.62$ & $8.39 \pm 6.72^{*}$ \\
$\quad$ Sunday & $9.00 \pm 2.96$ &
\end{tabular}

Data are reported as mean \pm SD (decimal system). Estimates were based on representative samples of 1000 adults per survey. Monday through Thursday data were pooled due to similarity.

${ }^{*} \mathrm{P}<0.05$ compared to corresponding (same week day) 1987 values (Student $t$-test). gender, age bracket, marital status, and socioeconomic status. There were fewer married people and fewer people belonging to the upper socio-economic level in 1995 than in 1987. There was also a significant increase in the proportion of people belonging to the lower class. The age distribution between surveys was similar.

\section{Sleep pattern}

There were slight, but significant changes in sleep behavior between 1987 and 1995, as shown in Table 2. Depending on the day of the week, the preferential time to go to bed varied from 22:00-22:50 in 1987 to 23:2024:00 in 1995, decreasing on Sunday. Time of waking up varied from $~ 6: 10-7: 00$ in 1987 to $\sim 6: 50-7: 40$ in 1995 (Table 2), increasing on Sunday. Total hours slept varied from 7.45-9.00 in 1987 to 7.40-8.40 in 1995 (Table 2). Overall, interviewees went to bed and woke up later in 1995 than in 1987. There also was a significant decrease in total hours slept in 1995 compared to 1987, on Saturdays and Sundays.

\section{Difficulty in initiating sleep}

In 1995, the general prevalence of difficulty initiating sleep showed a significant increase compared with the preceding survey $(Z=3.1, P<0.05$; Figure 1$)$. This was probably due to the increase observed among women $(Z=2.7, P<0.05)$, since among men the frequency also increased, but not significantly $(\mathrm{Z}=1.6, \mathrm{~ns})$. Women had the highest prevalence in both surveys $(1987: \mathrm{Z}=3.4, \mathrm{P}$ $<0.05 ; 1995: \mathrm{Z}=4.1, \mathrm{P}<0.05)$.

\section{Difficulty in maintaining sleep}

As shown in Figure 1, a significantly higher proportion of difficulty maintaining sleep was observed in 1995 than in 1987 (Z $=6.4, \mathrm{P}<0.05)$. A 2-fold increase was observed among men $(\mathrm{Z}=4.7, \mathrm{P}<0.05)$, and 
a relative increase of $60 \%$ among women $(\mathrm{Z}$ $=4.4, \mathrm{P}<0.05)$. This complaint prevailed among women, but only in the first survey (1987: $Z=2.7, \mathrm{P}<0.05 ; 1995: \mathrm{Z}=1.9, \mathrm{~ns})$.

\section{Early morning awakening}

As shown in Figure 1, the proportion of early morning awakening significantly increased from 1987 to 1995 ( $\mathrm{Z}=2.4, \mathrm{P}<$ $0.05)$ although an overlap between the 1987 and 1995 proportions was evident. Probably attributable to this, a significant change was no longer evident when the changes among men and among women were analyzed separately $(\mathrm{Z}=1.7$ and $\mathrm{Z}=1.8$, respectively, $\mathrm{P}=$ ns for both). This sleep complaint prevailed among women in both surveys (1987: $\mathrm{Z}=$ 2.4, $\mathrm{P}<0.05 ; 1995: \mathrm{Z}=2.3, \mathrm{P}<0.05)$.

\section{Excessive diurnal sleepiness and sleep attacks}

The frequency of excessive diurnal sleepiness did not change significantly from 1987 to 1995 ( $\mathrm{Z}=0.8, \mathrm{P}=\mathrm{ns}$; Figure 2 ). This complaint prevailed among women in the first survey $(Z=2.7, P<0.05$; males: $2.5 \%$, $95 \% \mathrm{CI}=1.7-3.7 \%$; females: $6.1 \%, 95 \% \mathrm{CI}=$ 4.8-7.8\%) but not in $1995(\mathrm{Z}=0.7, \mathrm{P}=\mathrm{ns}$; males: $3.3 \%, 95 \% \mathrm{CI}=2.4-4.6 \%$; females: $4.2 \%, 95 \% \mathrm{CI}=3.1-5.6 \%)$.
The frequency of sleep attacks also remained stable between 1987 and 1995 ( $\mathrm{Z}=$ $0.1, \mathrm{P}=\mathrm{ns}$, Figure 2), with comparable frequencies of about $3 \%$ for women and men.

\section{Parasomnias}

Habitual snoring was the most common complaint and was reported by about $20 \%$ of the interviewees, twice more often by men than by women. Nightmares, the second most prevalent parasomnia, were reported approximately by $10 \%$ of interviewees in both surveys, more frequently by women than by men.

The only change in parasomnia prevalence found from 1987 to 1995 was that of leg cramps, more frequently reported by women (Table 3).

\section{Physician consulting and the use of substances to help sleep}

A frequency of $12.5 \%(95 \% \mathrm{CI}=10.6-$ $14.7 \%$ ) of the interviewees in 1987 and of $10.8 \%(95 \% \mathrm{CI}=9.0-12.9 \%)$ in $1995 \mathrm{had}$ sought medical help for their sleep problems or had informed their physicians of sleep problems during evaluation of other problems $(\mathrm{Z}=1.2, \mathrm{P}=\mathrm{ns})$. In both surveys, significantly more women than men con-

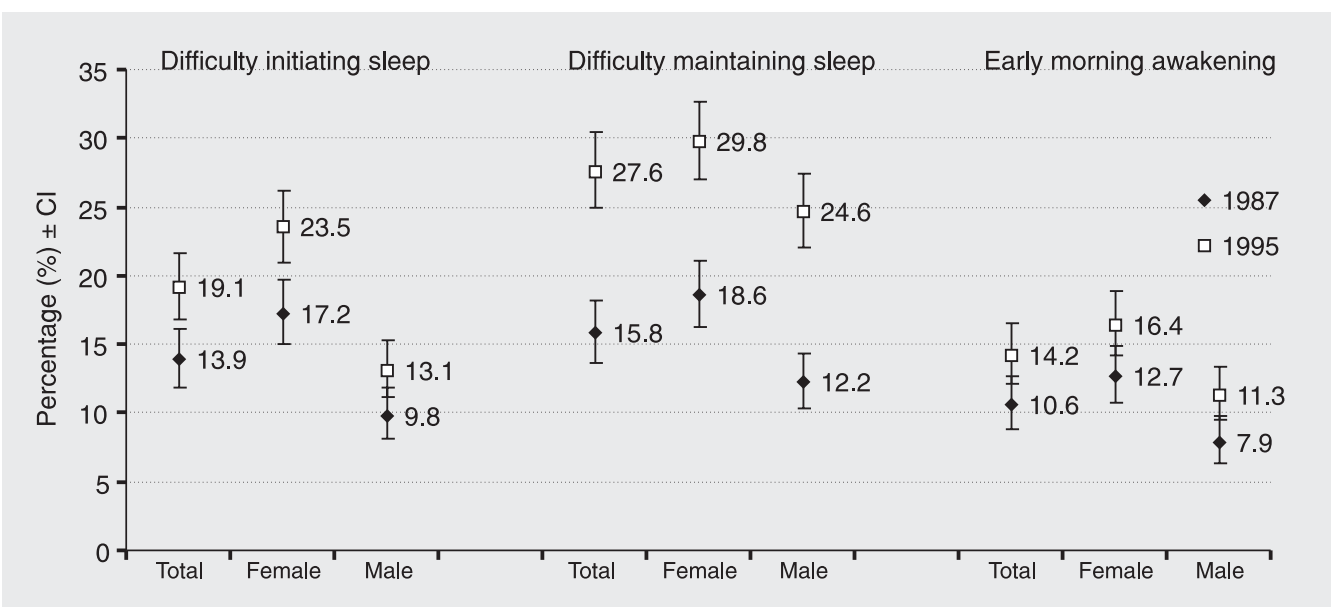

Figure 1. Insomnia complaints by gender in surveys carried out in 1987 and 1995 in the city of São Paulo. Estimates were based on representative samples of 1000 adults per survey. Data are reported as percentages \pm confidence interval $(\mathrm{Cl})$ at $95 \%(\mathrm{Z}-$ test). 
sulted physicians for their sleep problems (1987: $\mathrm{Z}=4.3, \mathrm{P}<0.05: 16.5 \%, 95 \% \mathrm{CI}=$ 14.3-18.9 vs $7.5 \%, 95 \% \mathrm{CI}=6.0-9.3 \%$; 1995 : $\mathrm{Z}=4.1, \mathrm{P}<0.05: 14.3 \%, 95 \% \mathrm{CI}=12.3-16.6$ vs $6.1 \%, 95 \% \mathrm{CI}=4.8-7.8 \%)$. The habitual use of sleep-promoting substances ( 3 or more nights per week) was reported by $3.9 \%$ $(95 \% \mathrm{CI}=2.9-5.3 \%)$ and $3.0 \%(95 \% \mathrm{CI}=$ $2.1-43 \%)$ of the interviewees in 1987 and 1995 , respectively $(Z=1.1, P=n s)$. In both surveys, women's use of sleep medicine was twice that of men $(1987: \mathrm{Z}=2.7, \mathrm{P}<0.05$;

Figure 2. Excessive sleep complaints in surveys carried out in 1987 and 1995 in the city of São Paulo. Estimates were based on representative samples of 1000 adults per survey. Data are reported as percentages \pm confidence interval $(\mathrm{Cl})$ at $95 \%(\mathrm{Z}$ test).

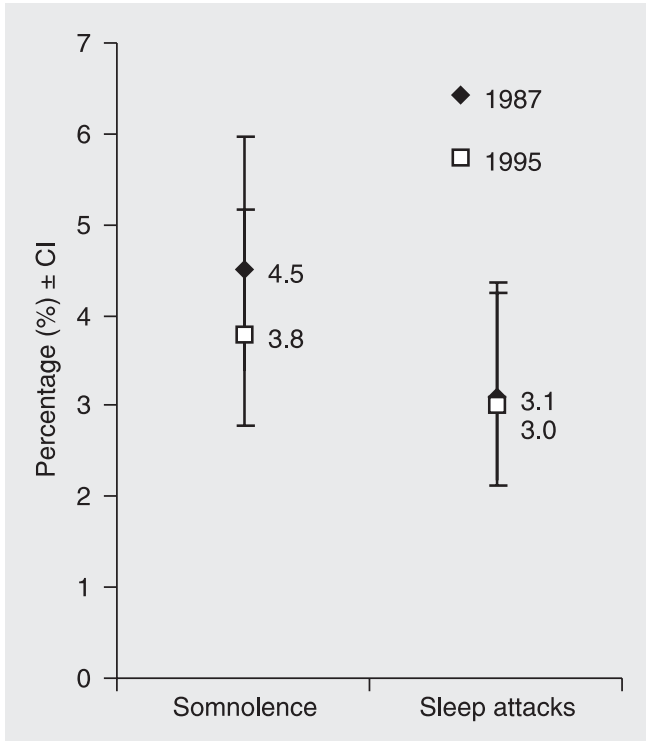

Table 3. Parasomnias and male:female ratio in surveys carried out in 1987 and 1995 in the city of São Paulo.

\begin{tabular}{|c|c|c|c|c|}
\hline & 1987 & $\begin{array}{c}1987 \\
\text { (male:female) }\end{array}$ & 1995 & $\begin{array}{c}1995 \\
\text { (male:female) }\end{array}$ \\
\hline Snoring & $21.5 \%(19.1-24.2)$ & 1:0.5 & $19.0 \%(16.7-21.6)$ & $1: 0.5$ \\
\hline Nightmares & $11.0 \%(9.2-13.1)$ & $1: 1.3$ & $8.5 \%(6.9-10.4)$ & $1: 1.7$ \\
\hline Bruxism & $3.2 \%(2.3-4.5)$ & 1:1.5 & $3.8 \%(2.8-5.2)$ & $1: 0.8$ \\
\hline Leg cramps & $2.6 \%(1.8-3.8)$ & $1: 1.8$ & $5.8 \%(4.5-7.4)^{*}$ & $1: 1.7$ \\
\hline Sleep paralysis & $1.8 \%(1.1-2.8)$ & $1: 1.2$ & $1.8 \%(1.1-2.8)$ & $1: 1.5$ \\
\hline Somnambulism & $0.8 \%(0.4-1.6)$ & $1: 1.3$ & $0.9 \%(0.4-1.7)$ & 1:0.9 \\
\hline
\end{tabular}

Data are reported as percent with confidence interval at $95 \%$ in parentheses. Estimates were based on representative samples of 1000 adults per survey. Prevalence values according to ICSD-2: snoring, $24 \%$ females, $40 \%$ males; nightmares, $2-8 \%$; bruxism, 3-8\%; leg cramps (age 60 years or over, 33\%); sleep paralysis, 5-6\% (any time during lifetime), $2.2 \%$ (at least monthly); somnambulism, $4 \%$ (any time during lifetime), $0.3 \%$ males, $0.1 \%$ females (monthly).

${ }^{*} \mathrm{P}<0.05$ compared to 1987 (Z-test).
$5.4 \%, 95 \% \mathrm{CI}=4.2-6.9$ vs $2.0 \%, 95 \% \mathrm{CI}=$ $1.3-3.1 \% ; 1995: \mathrm{Z}=2.2, \mathrm{P}<0.05 ; 4.0 \%$, $95 \% \mathrm{CI}=2.9-5.5$ vs $1.6 \%, 95 \% \mathrm{CI}=1.0-$ $2.6 \%)$.

\section{Discussion}

The results of the present study show a significant increase in the prevalence of insomnia complaints in the city of São Paulo in the 1995 survey compared to the preceding study conducted 8 years before. Specifically, difficulty falling asleep, difficulty staying asleep and waking up too early and not being able to fall back to sleep showed a relative increase of 37,75 , and $34 \%$, respectively. The same methodology was used in both inquiries. Thus, these changes cannot be attributable to variations in the definitions used to classify insomnia and somnolence complaints or to minimum sleep complaint frequencies per interviewee adopted as meaningful. One can raise the possibility that these changes may be reflecting an increasing public interest and awareness in sleep and its disorders, making them more readily recognizable, stimulated by the dissemination of medical information through the media. However, it is also possible that other events could be taking place. For instance, some investigators have found that higher income is associated with better sleep (3). More recently, Hyyppa et al. (11) showed an association between the quality of sleep in Finland and the economic recession during the period of 1991-1992, when the Finnish gross national product declined by $10 \%$. These investigators found that, compared to baseline data obtained 8 years before, prospectively unemployed persons suffered more from insomnia and used more hypnotic drugs than those continuously employed. Accordingly, some Brazilian socioeconomic aspects may help to clarify the differences between the two periods when the surveys were done. Compared to 1985, the gross national product per capita in São 
Paulo State over the three years preceding the latest survey (1995) declined by 10.5, 6.5 , and $2.5 \%$, respectively, and there was a relative increase of $47 \%$ in the unemployment rate in the city of São Paulo in 1994 (year preceding the last survey) (12). Although it is difficult to establish a direct association between socio-economic changes and sleep problems in our study, it seems very plausible to speculate that these negative economic factors have the potential to limit access to services such as health and education, both of which are factors related to sleep quality. Indeed, Travassos et al. (13) have recently shown that the use of Brazilian health services is dependent on family income, in such a way that people with higher income are more likely to use them.

In the latest survey (1995), difficulty maintaining sleep, difficulty initiating sleep and early morning awakening were found in approximately 28,19 , and $14 \%$ of interviewees, usually more frequently in women than in men. These results confirmed a female predisposition toward insomnia consistently found in epidemiological studies (14). Accordingly, in both surveys, women were more likely to use sleep medicine, a finding also typically observed in the literature on insomnia (15). Although being an increasingly recognized matter, the debate concerning the risk factors underlying the female preponderance of insomnia, such as the role of emotional disorders associated with sleep problems (particularly depression and anxiety, affective disorders known to occur more frequently among women) and the sex difference in reporting complaints (greater bodily vigilance among women leading them to be more likely to report symptoms), is still open $(14,15)$. Furthermore, in general, our data are consistent with epidemiological studies which also assessed insomnia symptoms based on their severity or on a frequency scale of at least three nights a week, criteria considered sensitive enough to reveal sleep complaints that are clinically meaningful (3). In France, 21\% complained of difficulties in initiating sleep and $16 \%$ complained of difficulty maintaining sleep (16). In Mexico, 25, 21, and 11\% reported trouble falling asleep, trouble staying asleep and early morning awakening (17) and, in Madrid, the corresponding frequencies were, 18,11 , and $9 \%$, respectively (18). Much lower rates, however, were found by Janson et al. (19) in Iceland, Sweden and Belgium: habitual difficulty falling asleep was reported by 6 to $9 \%$ of the interviewees and early morning awakening by 5 to $6 \%$. Ohayon and Smirne (20) and Ohayon and Hong (21), using the same methodology to evaluate sleep disorders in different communities, reported that difficulty initiating sleep, disrupted sleep and early morning awakening respectively affected 8, 19, and 7\% subjects among Italian people, while the figures for South Korea were 4,12 , and $2 \%$.

As to Brazil, our data closely agree with another Brazilian cross-sectional survey (22) conducted in 1996, that evaluated the prevalence of insomnia symptoms among adults living in the small community $(15,000$ inhabitants) of Bambuí. Similarly to our study, fragmented sleep was the most frequent complaint $(27 \%)$, followed by difficulty initiating sleep (18\%) and early morning awakening $(14 \%)$. Lower rates, however, were found in the city of Campo Grande (23), with 660,000 inhabitants, where difficulty in initiating sleep was the most prevalent sleep complaint (14.2\%), followed by sleep maintenance problems $(11.1 \%)$ and early morning awakening (9.3\%). São Paulo and Bambuí are in the same Southeastern region of Brazil, which is the wealthiest in the country, and, in spite of significant differences in size and economical activity, both have similar cultural backgrounds. Campo Grande, on the other hand, is a large city in the Central-Western region of Brazil, one of the poorest in the country, which differs considerably from the Southeastern region regarding cultural background, with a par- 
ticularly large population of indigenous people. The authors of the Campo Grande study have performed other sleep studies within indigenous tribes and have found a lower prevalence of insomnia (24). For example, in a survey carried out with 20 adult Bororo Indians, none had complained of insomnia in the previous week, no subject had ever sought treatment for insomnia or was regularly taking sleeping pills. Another three studies should be mentioned concerning sleep epidemiology in Brazil. Marchi et al. (25) studied the prevalence of insomnia in the adult population of another town in the Southeastern region of Brazil, São José do Rio Preto (population of 360,000 ), in a survey carried out in 2001. The overall insomnia level encountered was $32 \%$, which is very close to the $29.8 \%$ value obtained in the 1995 version of the present study. Blanco et al. (26) carried out an epidemiological study in the cities of São Paulo, Buenos Aires and Mexico City during the period from 1999 to 2000. They found no significant differences in the prevalence of sleep disorders between these cities, and therefore they pooled the data and detected moderate or severe insomnia in $25.4 \%$ of the individuals. Finally, Soldatos et al. (27), who carried out a oneday sleep survey on March 21, 2002, throughout the world, found that Brazil is the country that most differs regarding sleep disorders, having the population with the highest prevalence of 5 of 8 Athens Insomnia Scale symptoms rated as moderate to severe. According to the definition of primary insomnia by the Diagnostic and Statistical Manual of Mental Disorders (DSM-IV), on average, throughout the world, $12.1 \%$ subjects meet this criterion, whereas the prevalence is of $31.8 \%$ for Brazil (the highest found).

In the present study, the insomnia complaints may be associated with the changes in sleep behavior found between 1987 and 1995. In general, interviewees went to bed $(22: 29,1987 ; 22: 39,1995)$ and woke up $(6: 26,1987 ; 7: 04,1995)$ later in 1995 than in
1987. The time to go to bed most often found in a general survey in Brazil was of 22:00 and the time of waking up 6:00, a little earlier than the times found in São Paulo (27). The total hours slept also varied, having decreased slightly from an average of 8.0 (1987) to $7.7 \mathrm{~h}$ (1995). Other investigators have reported similar total sleeping hours: 7 h for São Paulo (similar to Mexico City and Buenos Aires) (27) and $8.2 \mathrm{~h}$ for Brazil in general (26). There are indications that the modern world requires people to sleep less and less and the surveys described here, carried out within an interval of 8 years, may be significant to show this change. Future surveys are necessary to evaluate how these changes will evolve. According to Bonnet and Arand (28), modern society is chronically sleep deprived, with a third of the population showing significant sleep loss. Sleep extension studies show that average young adults should sleep $8.5 \mathrm{~h}$ per night, whereas reported sleep lengths of 7.2-7.4 h are deficient. The average sleeping hours found in São Paulo are intermediate, indicating that sleep deprivation is probably prevalent.

Differently from the pattern found for insomnia symptoms, the frequencies of excessive somnolence and sleep attacks remained stable, around 3-4\% between the two surveys. These estimates are in consonance with past and recent studies in American, European and Asian countries, showing that somnolence affects 5.5 to $21.5 \%$ of the population, while 0.5 to $10 \%$ complain of sleep attacks $(17,19,29,30)$.

The overall prevalences of parasomnias (Table 3) were consistent with those expected according to the International Classification of Sleep Disorders (ICSD-2) (31) which indicates that the survey methods and results are within international criteria. The ICSD-2 values for leg cramps, sleep paralysis and somnambulism are higher, but correspond to mild forms of these conditions. Our survey considered moderate and severe con- 
ditions only, which are similar to corresponding moderate and severe values from surveys used as reference by ICSD-2.

Habitual snoring was reported by approximately $20 \%$ of the interviewees in our surveys, twice more often among men than among women. These proportions are higher than the range of $12-16 \%$ observed in Sweden, Mexico and Spain, and lower than the $28 \%$ proportion observed in Hispanic-Americans $(17,18,22,32-34)$.

Nightmares were reported by 11 and $8 \%$ of the population in 1987 and 1995, respectively. These proportions are within the range of 8 to $12 \%$ reported by others $(18,33)$. Also, the $1 \%$ proportion found for somnambulism closely approximates the estimates of 1 to 2.5\% obtained for North American and Spanish samples $(17,18,33)$.

Bruxism was reported by about $4 \%$ of the interviewees in the 1995 survey. Although epidemiologic studies about this parasomnia in the general population are very scarce, estimates from Mexico and Canada show a range of $0.7 \%$ (17) to $8 \%$ (35). We found that almost $2 \%$ of the interviewees reported having sleep paralysis at least once a month, an estimate close to the frequency of $1.4 \%$ found by Ohayon et al. (36) and within the reported range of 0.3 to $11 \%(17,18)$.

The prevalence of leg cramps in the general population is not well known but our findings of 2.6 and $5.8 \%$ are much higher than the almost $1 \%$ reported by Ohayon et al. (36). The increase in prevalence of this parasomnia from 1987 to 1995 merits further study, although several factors must be investigated. Studies show that nocturnal leg cramps are frequent in elderly people and equally prevalent in men and women. Results suggest that there is co-morbidity between leg cramps and medical and neurological diseases, including periodic limb movement, diabetes and peripheral vascular disease (37-39). Nocturnal leg cramps are also associated with intake of alcohol, medications and blood levels of thyroid hormones, urea, creatinine, potassium, magnesium, calcium, and glucose (39). Therefore, many facts may explain the increase in nocturnal leg cramp prevalence from 1987 to 1995 , such as the worldwide growing prevalence of metabolic syndrome, associated with diabetes and nutritional behavior.

The proportion of individuals who had consulted a physician due to sleep problems or had mentioned them to their physicians remained unchanged between surveys, at about $12 \%$. Since this proportion is lower than the proportion of individuals complaining of sleep difficulties, we can infer that sleep complaints are under-detected by healthcare professionals. A study carried out in the US at five managed care organizations indicated that only $0.9 \%$ of patients were seeing physicians due to sleep problems, although $13.5 \%$ had difficulty initiating or maintaining sleep and $32.5 \%$ had insomnia with daytime dysfunction (40). Therefore, although the population of São Paulo sought medical help for sleep problems at a lower frequency than probably required, there was a lower level of discrepancy compared to the American population. It is also worth mentioning that, according to information provided by the São Paulo Sleep Institute (July 2005, inquiry of registered healthcare organizations), in 1987 there were only two polysomnography units set up in the city of São Paulo, both at a private hospital. By 1995, this number had increased to 16 , ten of which in public organizations. Today, there are 89 units in São Paulo city and 185 in the whole of Brazil. Although this indicates that both public and private health care providers are growingly aware of the importance of sleep disorders, the facilities for adequate diagnosis are still scarce. For example, by 1995 , $27.6 \%$, or 1.7 million, inhabitants of São Paulo complained of difficulty maintaining sleep and yet, at full capability, only 5840 $(0.3 \%)$ could be evaluated by polysomnography per year.

The overall results from our study showed 
that sleep complaints in the general population of São Paulo City have increased significantly from 1987 to 1995 . The latter profile shows that insomnia is quite common, with a profile close to what is observed in communities from North America, Europe and Asia. Whatever the causes are and whether a pattern of increasing prevalence in insomnia symptoms will persist remain the subject of future research.

Epidemiological data are needed for a variety of reasons, such as knowledge on prevalence, gender ratios and age-related trends for the development of health care and educational strategies by health care providers and health agencies. Few epidemiological studies have been carried out by the same research group and following the same methodology at different times, as presented here. This type of survey has the advantage of also indicating trends in sleep disorders. We hope that the findings reported here have contributed to shed more light on the epidemiology of sleep problems, particularly in South American communities.

\section{References}

1. Hublin CG, Parninen MM. The extent and impact of insomnia as a public health problem. Primary care companion. J Clin Psychiatry 2002; 4 (Suppl 1): 8-12.

2. Roth T, Roehrs T, Costa e Silva JA, Chase MH. Public health and insomnia: consensus statement regarding its status and needs for future actions. Report of an International Consensus Conference, October 1996. Sleep 1999; 22 (Suppl 3): S417-S420.

3. Ohayon MM. Epidemiology of insomnia: what we know and what we still need to learn. Sleep Med Rev 2002; 6: 97-111.

4. Braz S, Neumann BRB, Tufik S. Evaluation of sleep disorders: elaboration and validation of a questionnaire. Rev ABP-APL 1987; 9: 9-14.

5. Largest agglomerations in the world, geoHIVE. http://www. geohive.com/charts/city_agg1950_2015.php. Accessed July 11, 2005.

6. IBGE Instituto Brasileiro de Geografia e Estatística. www.ibge. gov.br. Accessed July 11, 2005.

7. Bussab WO. Pesquisa de emprego e desemprego SEADE/DIEESE: regiões homogêneas da grande São Paulo. Rev Fund SEADE/S Paulo Perstect 1985; 1: 5-11.

8. Partinen M, Rimpelä M. Sleeping habits and sleep disorders in a population of 2,016 Finnish adults. In: Anonymous, The Yearbook of Health Education Research 1982. Helsinky: The National Board of Health; 1982. p 253-260.

9. Karacan I, Thornby J, Williams R. A community survey. In: Guilleminault C, Lugaresi E (Editors), Sleep/Wake Disorders: Natural history, epidemiology, and long-term evolution. New York: Raven Press; 1983. p 37-60.

10. Rutter M. Pesquisa de mercado. São Paulo: Editora Ática; 1988.

11. Hyyppa MT, Kronholm E, Alanen E. Quality of sleep during economic recession in Finland: a longitudinal cohort study. Soc Sci Med 1997; 45: 731-738.

12. Anuário Estatístico do Estado de São Paulo (Estado de São Paulo: 1985-99) e Pesquisa de Emprego e Desemprego na Região Metropolitana de São Paulo, 1985-2002. www.seade.gov.br. Accessed January 25, 2004.

13. Travassos C, Viacava F, Pinheiro R, Brito A. Utilization of health care services in Brazil: gender, family characteristics, and social status. Rev Panam Salud Publica 2002; 11: 365-373.

14. Zhang B, Wing YK. Sex differences in insomnia: a meta-analysis. Sleep 2006; 29: 85-93.

15. Krishnan V, Collop NA. Gender differences in sleep disorders. Curr Opin Pulm Med 2006; 12: 383-389.

16. Leger D, Guilleminault C, Dreyfus JP, Delahaye C, Paillard M. Prevalence of insomnia in a survey of 12,778 adults in France. $J$ Sleep Res 2000; 9: 35-42.

17. Lopez AT, Sanches MEG, Torres FG, Ramirez MPN, Olivares MVS. Habitos y trastornos del dormir en residentes del area metropolitana de Monterrey. Salud Mental 1995; 18: 14-22.

18. Vela-Bueno A, De Iceta M, Fernandez C. Prevalence of sleep disorders in Madrid, Spain. Gac Sanit 1999; 13: 441-448.

19. Janson C, Gislason T, De Backer W, Plaschke P, Bjornsson E, Hetta J, et al. Prevalence of sleep disturbances among young adults in three European countries. Sleep 1995; 18: 589-597.

20. Ohayon MM, Smirne S. Prevalence and consequences of insomnia disorders in the general population of Italy. Sleep Med 2002; 3: 115120.

21. Ohayon MM, Hong SC. Prevalence of insomnia and associated factors in South Korea. J Psychosom Res 2002; 53: 593-600.

22. Rocha FL, Guerra HL, Lima-Costa MF. Prevalence of insomnia and associated socio-demographic factors in a Brazilian community: the Bambuí study. Sleep Med 2002; 3: 121-126.

23. Souza JC, Magna LA, Reimao R. Insomnia and hypnotic use in Campo Grande general population, Brazil. Arq Neuropsiquiatr 2002; 60: 702-707.

24. Reimão R, Souza JC, Guerra HL, Gaudioso CEV. Hábitos do sono e insônia em indígenas Bororó adultos, em sono, sonho e seus distúrbios. São Paulo: Frôntis; 1999.

25. Marchi NS, Reimao R, Tognola WA, Cordeiro JA. Analysis of the prevalence of insomnia in the adult population of São José do Rio Preto, Brazil. Arq Neuropsiquiatr 2004; 62: 764-768.

26. Blanco M, Kriber N, Cardinali DP. A survey of sleeping difficulties in an urban Latin American population. Rev Neurol 2004; 39: 115-119.

27. Soldatos CR, Allaert FA, Ohta T, Dikeos DG. How do individuals 
sleep around the world? Results from a single-day survey in ten countries. Sleep Med 2005; 6: 5-13.

28. Bonnet $\mathrm{MH}$, Arand $\mathrm{DL}$. We are chronically sleep deprived. Sleep 1995; 18: 908-911.

29. Partinen M, Hublin CG. Epidemiology of sleep disorders. In: Kryger $\mathrm{MH}$, Roth T, Dement WC (Editors), Principles and practice of sleep medicine. 3rd edn. Philadelphia: W.B. Saunders Company; 2000. p 558-579.

30. Liu X, Uchiyama M, Kim K, Okawa M, Shibui K, Kudo Y, et al. Sleep loss and daytime sleepiness in the general adult population of Japan. Psychiatry Res 2000; 93: 1-11.

31. American Academy of Sleep Medicine. International Classification of Sleep Disorders Diagnostic and Coding Manual (ICSD-2). 2nd edn. Westchester: American Academy of Sleep Medicine; 2005.

32. Schmidt-Nowara WW, Coultas DB, Wiggins C, Skipper BE, Samet JM. Snoring in a Hispanic-American population. Risk factors and association with hypertension and other morbidity. Arch Intern Med 1990; 150: 597-601.

33. Bixler EO, Kales A, Soldatos CR, Kales JD, Healey S. Prevalence of sleep disorders in the Los Angeles metropolitan area. Am J Psychiatry 1979; 136: 1257-1262.
34. Gislason T, Almqvist M, Eriksson G, Taube A, Boman G. Prevalence of sleep apnea syndrome among Swedish men - an epidemiological study. J Clin Epidemiol 1988; 41: 571-576.

35. Lavigne GJ, Montplaisir JY. Restless legs syndrome and sleep bruxism: prevalence and association among Canadians. Sleep 1994; 17: 739-743.

36. Ohayon MM, Zulley J, Guilleminault C, Smirne S. Prevalence and pathologic associations of sleep paralysis in the general population. Neurology 1999; 52: 1194-1200.

37. Naylor JR, Young JB. A general population survey of rest cramps. Age Ageing 1994; 23: 418-420.

38. Ehrenberg BL. Sleep pathologies associated with nocturnal movements. In: Young RR (Editor), Movement disorders in neurology and neuropsychiatry. Oxford: Blackwell Scientific Publication; 1992. p 634-648.

39. Butler JV, Mulkerrin EC, O’Keeffe ST. Nocturnal leg cramps in older people. Postgrad Med J 2002; 78: 596-598.

40. Hatoum HT, Kania CM, Kong SX, Wong JM, Mendelson WB. Prevalence of insomnia: a survey of the enrollees at five managed care organizations. Am J Manag Care 1998; 4: 79-86. 